\title{
Association of MYF5 gene allelic variants with production traits in pigs
}

\author{
Fausto Moreira da Silva Carmo ${ }^{1}$, Simone Eliza Facioni Guimarães ${ }^{1}$, Paulo Sávio Lopes ${ }^{1}$, \\ Aldrin Vieira Pires ${ }^{1}$, Marta Fonseca Martins Guimarães ${ }^{2}$, Marcos Vinícius Gualberto Barbosa da Silva ${ }^{2}$, \\ Alex Sandro Schierholt ${ }^{1}$, Kleibe de Moraes e Silva ${ }^{1}$ and Lúcio Alberto de Miranda Gomide ${ }^{3}$ \\ ${ }^{1}$ Universidade Federal de Viçosa, Departamento de Zootecnia, Viçosa, MG, Brazil. \\ ${ }^{2}$ EMBRAPA Gado de Leite, Juiz de Fora, MG, Brazil. \\ ${ }^{3}$ Departamento de Tecnologia de Alimentos, Universidade Federal de Viçosa, Viçosa, MG, Brazil.
}

\begin{abstract}
We studied the phenotypic effects of polymorphisms at the MYF5 gene in a divergent $F_{2}$ swine population and found that one polymorphism was due to an insertion and another to a deletion. The genotypes of 359 F2 animals were obtained and the Normal/Normal (NN) and Normal/Insertion (NI) genotypes analyzed to determine associations with phenotypic data for performance, carcass and meat quality traits. Significant differences were observed $(p<0.05)$ between $\mathrm{NN}$ and $\mathrm{NI}$ animals for drip ( $\mathrm{NN}=3.14 \pm 1.56$; $\mathrm{NI}=3.69 \pm 2.78 \%$ ), cooking ( $\mathrm{NN}=32.26 \pm 2.41$; $\mathrm{NI}=33.21 \pm 2.31 \%)$ and total loss $(\mathrm{NN}=34.16 \pm 2.63$ and $\mathrm{NI}=34.97 \pm 2.08 \%)$. The Deletion marker was not statistically tested. The results indicate that the allelic variant Insertion is associated with a deleterious effect on meat quality traits and should be monitored in marker assisted selection programs.
\end{abstract}

Key words: myogenesis, DNA sequencing, pig production, PCR.

Received: March 22, 2004; Accepted: March 23, 2005.

\section{Introduction}

Meat is the result of the transformation of muscle cells into an edible product after an animal has been slaughtered. Muscle consists of a large number of fibers which themselves are made up of smaller fibrils, muscle mass being the sum of all the individual cellular processes and cellular growth occurring within the muscle. During the fetal period muscles grow due to cell proliferation (hyperplasia) but from birth until slaughter the growth of muscle cells no longer depends on the division of the cell nucleus but on an increase in the size and diameter of the cytoplasm (a hypertrophy). Cell proliferation may occur during hypertrophy but only in satellite cells.

Genes in the MyoD family (MYOD, MYF5, myogenin and MYF6) are related to mammalian muscle development, with the MYOD, MYF5 and myogenin genes being involved in prenatal hyperplastic processes and the MYF6 gene to postnatal muscle growth (te Pas et al ., 1999a). Myogenin is required for the myoblast differentiation established by the initial expression of the MYF5 or MYOD genes which are thus responsible for the determination and specialization of myoblasts, so myogenin could be

Send correspondence to Simone E.F. Guimarães. Universidade Federal de Viçosa, Departamento de Zootecnia, 36571-000 Viçosa, MG, Brazil. E-mail: sfacioni@ufv.br. considered to be a differentiation factor (Bergstrom and Tapscott 2001). Studies on the MyoD gene family (especially the MYOD and MYF5 genes) are still rare in pigs, although a study has been carried out on two commercial pig lines by te Pas et al. (1999a) who analyzed a Hinf I polymorphic site in the second intron of the MYF5 gene to determine the effects of genetic variation at this site on desirable traits but found no genotypically associated differences for any of the traits investigated (birth weight, weight at slaughter, growth rate, meat weight and subcutaneous fat thickness).

During the study reported in the present paper, we sequenced the MYF5 gene from both sexes of the parental generation of an $\mathrm{F}_{2}$ crossed pig population. This parental population was constituted of Brazilian Piau boars and commercial white females. The $\mathrm{F}_{2}$ offspring were genotyped to identify the allelic variants and the genotypes were evaluated statistically for associations with various performance, carcass and meat quality traits.

\section{Material and Methods}

The experiment was conducted on the Pig Breeding Farm of the Animal Science Department, Universidade Federal deViçosa (UFV), Viçosa, Minas Gerais, Brazil. Except for both parental boars (Brazilian Piau Breed), all other 
animals (18 parental sows, 11 Landrace $\mathrm{x}$ Large White and 7 Landrace $x$ Large White $x$ Pietrain, $F_{1}$ and $F_{2}$ animals) were maintained on the farm from birth until the time of slaughter. Animals were slaughtered by first applying an approved electric shock and then bled immediately using cardiac puncture. After cleaning and evisceration, the carcasses were divided into two halves, the left half being refrigerated at $4{ }^{\circ} \mathrm{C}$ for $24 \mathrm{~h}$. Genetic analyses were performed at the Laboratory of Animal Biotechnology, Animal Science Department, UFV.

Blood was collected at the time of slaughter from each animal $\left(F_{0}\right.$ parents and their $F_{1}$ and $F_{2}$ offspring), treated with proteinase $\mathrm{K}$ and the genomic DNA extracted from white blood cells using the phenolchloroform technique. The DNA in each sample was quantified spectrophotometrically $(\lambda=260$ and $280 \mathrm{~nm})$ and 200 to $300 \mu \mathrm{L}$ aliquots diluted in TE buffer (10 $\mathrm{mmol} / \mathrm{L}$ Tris- $\mathrm{HCl}, \mathrm{pH} 8.0$, and $1 \mathrm{mmol} / \mathrm{L}$ EDTA, $\mathrm{pH} 8.0$ ) to a concentration of $25 \mathrm{ng} \mathrm{DNA} / \mu \mathrm{L}$ and kept at $4{ }^{\circ} \mathrm{C}$. A DNA stock solution from each animal was also diluted in TE and stored at $-20^{\circ} \mathrm{C}$.

The primers were designed using the WebPrimers program (http://alces.med.umn.edu/websub.html) and covered exon I (665 bp), exon II (75 bp) and exon III (791 bp) at the end of the gene. The MYF5 gene sequence (GenBank accession number Y17154) was used as the consensus sequence. Six primer pairs were constructed, the primers being selected according to Rychlik's (1993) criteria based on their position in the gene, annealing temperatures and variation in free energy $(\Delta G)$.

Each amplification reaction consisted of $1 \mathrm{U}$ Taq DNA polymerase, $0.2 \mathrm{mmol} / \mathrm{L}$ dNTPs, $0.2 \mu \mathrm{mol} / \mathrm{L}$ of each forward and reverse primer, $20 \mathrm{mmol} / \mathrm{L}$ Tris- $\mathrm{HCl}$,

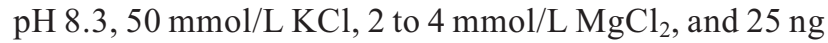
genomic DNA in a total volume of $100 \mu \mathrm{L}$. The amplification program varied according to each primer pair and basically consisted of the following steps: denaturation at $94{ }^{\circ} \mathrm{C} / 1 \mathrm{~min}$, mean annealing temperature of $64^{\circ} \mathrm{C} / 1$ $\min$ (according to the primer pair), and extension temperature of $72{ }^{\circ} \mathrm{C} / 1 \mathrm{~min}$, with 35 cycles of repetition. Successful amplification was determined on polyacrylamide gels stained with silver nitrate. The primers used in the amplification reactions and for sequencing are listed in Table 1.

To optimize the sequencing reactions, three pools (1, 2 and 3) of amplified DNA from parental sows were obtained for each fragment after amplification, sow DNA being used because it was expected that the MYF5 gene sequence would be conserved in these animals. Both parental boars were sequenced individually. Approximately $100 \mu \mathrm{L}$ of amplified material from each pool and from both parental boars was purified on GFX ${ }^{\mathrm{TM}}$ PCR DNA columns using the Gel Band Purification kit (Amersham Pharmacia Biotech). After purification, the DNA sample was quanti-
Table 1 - Primer sets used in the study, annealing position within the MYF5 gene and expected fragment size.

\begin{tabular}{lllc}
\hline Primer & Sequence & Position* & $\begin{array}{c}\text { Size }^{* *} \\
(\mathrm{bp})\end{array}$ \\
\hline F1 & AGAAGTCGGAGCTTCGGAGC & $179-198$ & 449 \\
R1 & CCCCGCTTACTTGCGCTGTTTA & $606-627$ & \\
F2 & AACGTTGGATTTCCTTCGTTCC & $544-565$ & 566 \\
R2 & CCACTCGTGGCTCAAACTCG & $1090-1109$ & \\
F3 & GGACGAGTTTGAGCCACGAGTGG & $1087-1109$ & 495 \\
R3 & GGTTFCTACACCTGCTTAAACG & $1562-1581$ & \\
F4 & CAGAGCACCTTTCGCCAAGA & $2249-2268$ & 159 \\
R4 & TCCTCTAAAGGCGTTCGTTCT & $2387-2407$ & \\
F5 & AGGGCAACGTAAGCAAGTCTACC & $2729-2751$ & 536 \\
R5 & CCCTTGGATGAATTGCCCCTATAAG & $3240-3264$ & \\
F6 & TTCTTTTCCTTTGTCTTGGCATTAA & $3190-3214$ & 479 \\
R6 & ACGTATCAATCACTGCCAATGCTA & $3646-3669$ & \\
\hline
\end{tabular}

*The position of the primers was established based on GenBank sequence Y17154.

**Expected size of the fragments after amplification according to the same sequence.

fied in a Genequant II DNA/RNA spectrophotometer (Amersham Pharmacia Biotech) at $\lambda=260$ and $280 \mathrm{~nm}$ using a wavelength of $320 \mathrm{~nm}$ for background compensation. The remaining purified DNA was stored at $-20{ }^{\circ} \mathrm{C}$ until sequencing.

The DNA from the parental animals was sequenced by the dideoxynucleotide (ddNTPs) chain termination technique using the ABI PRISM BigDye Terminator Cycle Sequence Ready Reaction kit (Applied Biosystems). Briefly, in each reaction $20 \mathrm{ng}$ of sample DNA was mixed with $2 \mu \mathrm{L}$ of the sequencing solution provided with the Applied Biosystems Sequencing kit, 5.0 pmol of the same direct primer as was used in the amplification reaction and $2 \mu \mathrm{L}$ of buffer $(200 \mathrm{mM}$ Tris- $\mathrm{HCl}, \mathrm{pH} 9.0$, $5 \mathrm{mM} \mathrm{MgCl}_{2}$ ) in a total reaction volume of $10 \mu \mathrm{L}$. A similar reaction mix was prepared for the reverse primer. After the sequencing reaction, the pellet was resuspended in $15 \mu \mathrm{L}$ hi-di formamide (Applied Biosystems), denatured at $95{ }^{\circ} \mathrm{C}$ for $5 \mathrm{~min}$ and kept on ice until application to an automatic ABI PRISM 310 sequencer. The generated sequences were edited and mounted in contigs using the SEQ MAN II program (DNASTAR, Inc.), and then aligned and compared to each other and to the Y17154 sequence using the DNASTAR program (DNASTAR Inc).

To produce the 359 pigs in the $\mathrm{F}_{2}$ generation, $54 \mathrm{~F}_{1}$ sows and $11 \mathrm{~F}_{1}$ boars were randomly selected and intercrossed. Although the $F_{1}$ animals were not phenotypically evaluated, their MYF5 genotypes were determined in a $20 \mu \mathrm{L}$ reaction volume, under similar PCR conditions as those used for the parental animals. For this experiment, phenotypic data from $359 \mathrm{~F}_{2}$ animals resulting 
from the initial crossing of commercial sows with native Brazilian boars were analyzed with the MYF5 gene fragments being amplified in a $20 \mu \mathrm{L}$ reaction volume under similar conditions to those used for the parental generation. After amplification $5 \mu \mathrm{L}$ of each amplification product was subjected to silver nitrate-stained polyacrylamide gel electrophoreses (AgPAGE).

Performance traits measured in the $\mathrm{F}_{2}$ generation were: birth weight $(\mathrm{BW})$; weight at 21 days $\left(\mathrm{W}_{21}\right), 77$ days $\left(\mathrm{W}_{77}\right)$ and $105\left(\mathrm{~W}_{105}\right)$; weight at slaughter (WS); average daily gain (ADG); feed intake (FI); feed-gain ratio (FG) from 77 to 105 days of age and age at slaughter (AS). Carcass traits measured in the $\mathrm{F}_{2}$ generation: carcass length (MLC); backfat thickness at last 2nd-3rd thoracic vertebrae $(\mathrm{SH})$; backfat thickness after last rib, at $6.5 \mathrm{~cm}$ from the midline (P2); loin depth (LD); loin eye area (LEA); total ham weight (THW); skinless and fatless ham weight (HW); total (bone in) loin weight (TLW); loin weight (LW) and carcass yield (CY). The $359 \mathrm{~F}_{2}$ animals were slaughtered at approximately $65 \mathrm{~kg}$ of live weight. The meat quality traits determined in the longissimus dorsi muscle were: $\mathrm{pH} 45 \mathrm{~min}$ after slaughter $(\mathrm{pH} 45), \mathrm{pH} 24$ hours after slaughter (pH24), intramuscular fat content (IMF), drip loss (DL), cooking loss (CL), total loss (TL), objective tenderness (OT), and color. Meat color was determined with the Hunter Lab system and included the spectrophotometric measurement of lightness (L), redness (A), yellowness (B), hue angle (h), and chroma (c).

Correlation between genotype and traits was performed using the PROC GLM module of the SAS program based on the model

$$
y_{i j k l}=S_{i}+G_{j}+L_{k}+\left(C_{i j k l}-\bar{C}\right) b+e_{i j k l}
$$

where $y_{i j k l}$ equals the observation, $S_{i}$ the sex effect $I$ ( ${ }_{i}$ being 1 for boars, 2 for sows), $G_{j}$ the genotype effect ( $j$ being 1 for $\mathrm{NN}, 2$ for NI), $L_{k}$ the batch effect $j$ ( ${ }_{j}$ being $\left.1,2,3,4,5\right)$, $\left(C_{i j k l}-\bar{C}\right) b$ the covariate and $e_{i j k l}$ the random error. The covariates were litter size at birth weight, litter size at weaning for $\mathrm{W}_{21}, \mathrm{~W}_{77}, \mathrm{~W}_{105}$ and $\mathrm{WS}$; weight at 77 days for $\mathrm{ADG}$, FG, FI, carcass weight for all carcass traits and AS for the meat quality traits. The difference between genotypes was tested by analysis of variance (F test) at the with the 5\% significance level.

\section{Results}

\section{Identification of mutations in the porcine MYF5 gene}

We sequenced three exons of the MYF5 gene in the 18 commercial sows and 2 native Brazilian boars which made up the parental generation. Polymorphisms were only detected for fragments amplified using primer pair number 6 (F6 and R6). Even before sequencing, AgPAGE showed not only an amplified product differing in size from the expected fragment (479 bp) in one of the parental boars and in pools 1 and 3, but also heteroduplex formations. In view of the electrophoretic differences in pools 1 and 3, these pools were examined and the product of each female was individually sequenced. No variation in the electrophoretic or sequencing pattern were detected for pool 2.

Multiple alignment of the parental sow and boar sequences with sequence Y17154 revealed two previously unreported variants, both demonstrable by AgPAGE and confirmable by fragment sequencing. The first variant was identified in a parental boar denominated 'boar C' and in sow number 211 and corresponded to a heterozygous TTT deletion (Figure 1) at positions 3420-3422 and characterized by the occurrence of heteroduplex bands. In addition to the $479 \mathrm{bp}$ expected fragment, we also amplified a second 476 bp fragment which had not been previously identified and which we named the 'Deletion' (D) sequence before submitting it to the GenBank database where it was assigned the accession number AY312362.

The second variant was identified in two parental sows (numbers 151 and 154 from the Landrace $\mathrm{x}$ Large White $\mathrm{x}$ Pietrain genetic group), from which we obtained a larger amplified fragment. Sequencing and alignment demonstrated that both sows were homozygous for an ATG trinucleotide insertion at position 3326 and for an A nucleotide deletion at position 3357, which resulted in a previously unreported $481 \mathrm{bp}$ amplified fragment (Figure 2) which we named the 'Insertion' (I) sequence before submitting it to the GenBank database where it was assigned the accession number AY285781.

We had established that the genotypes would be classified according to the allelic variants as: normal/normal $(\mathrm{NN})$; normal/insertion (NI); normal/deletion (ND); insertion/deletion (ID); insertion/insertion (II); and deletion/deletion (DD).

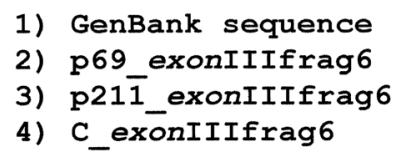

Figure 1 - Partially sequenced region of the fragment amplified with the F6-R6 primer pair. The region comprises nucleotides 3382 to 3438 according to the Y17154 GenBank sequence. Line 1: GenBank sequence; line 2: sequence found in parental animals represented here by the sequence of female p69; lines 3 and 4: sequences obtained for female p211 and male C, respectively. Gray shadow indicates the region of deleted nucleotides. A deletion (*) is present in the three parental sequences compared to the consensus sequence (line 1). Since this supposed deletion was present in all animals sequenced, it was not considered for the analysis.

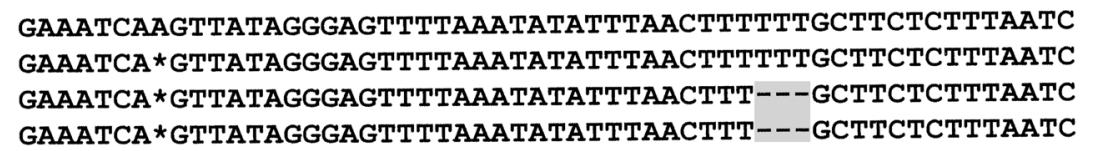



1) GenBank sequence
2) p147 exonIIIfrag6
3) p151-exonIIIfrag6
4) p154_exonIIIfrag6

\begin{abstract}
ACСTCTG---TTTAGAGCTTTATTTTTTCCCCTTTAAAAATATTAGAACAAATACTAGA ACCTCTG--TTTAGAGCTTTATTTTTTTCCCCTTTAAAAATATTAGAACAAATACTAGA ACCTCTGATGTTTAGAGCTTTATTTTTTTCCССTTAAAA-TATTAGAACAAATACTAGA ACСTCTGATGTTTAGAGCTTTATTTTTTCCCCTTTAAAA-TATTASAACAAATACTAGA
\end{abstract}

Figure 2 - Partially sequenced region of the fragment amplified with the F6-R6 primer pair. The region comprises nucleotides 3319 to 3378 according to the Y17154 GenBank sequence. Line 1: GenBank sequence; line 2: sequence found in parental animals represented here by the sequence of female p147; lines 3 and 4: sequences obtained for females p151 and p154, respectively. Inserted nucleotides are underlined and the region of deleted nucleotides is indicated by gray shadow.

\section{Genotyping of the $F_{1}$ generation}

The F2 generation was produced by randomly mating $11 \mathrm{~F}_{1}$ boars (none of which had ND genotypes) with $54 \mathrm{~F}_{1}$ sows (only 12 of which had ND genotypes). Only three $\mathrm{F}_{1}$ sows were mated to $\mathrm{NN}$ boars and two $\mathrm{F}_{1}$ sows were mated with NI boars to produce ND $F_{2}$ piglets, this small number being partly explainable by the fact that of the nearly $800 \mathrm{~F}_{2}$ animals born, only 359 were genotyped and had their phenotypes evaluated during the study. The DD genotype did not occur in the $\mathrm{F}_{2}$ generation because no ND boars were used in the $\mathrm{F}_{1}$ matings. Also, no II genotype was found in the analyzed $\mathrm{F}_{2}$ animals.

\section{Genotyping of the $\mathrm{F}_{2}$ generation}

The observed $\mathrm{F}_{2}$ genotypes were $\mathrm{NN}=264(73.5 \%)$, $\mathrm{NI}=86(24 \%), \mathrm{ND}=5(1.4 \%)$ and $\mathrm{ID}=4(1.1 \%)$, no type II or DD genotypes being detected in our sample. Since the NN and NI genotypes were the most frequent we excluded the other genotypes from the statistical analysis of the association with phenotypic traits.

The effect of the MYF5 variant on performance, carcass and meat quality traits

There were no statistically significant differences between the NN and NI genotypes on performance or carcass traits but there were statistically significant differences between the genotypes for the following meat quality traits: drip loss, 3.69\% for NN compared with $3.14 \%$, for NI ( $\mathrm{p}=0.028$ ); cooking loss, $33.21 \%$ for NN compared with $32.26 \%$ for NI ( $p=0.003)$; and total loss $34.97 \%$ for $\mathrm{NN}$ compared with $34.16 \%$ for NI $(\mathrm{p}=0.024)$ (Table 2$)$.

\section{Discussion}

Our study demonstrates that native Brazilian pigs have not yet been fully evaluated using genetic analysis. Little is known regarding the origin of Brazilian pig breeds but it has been speculated that during colonization of Brazil the Portuguese brought pigs which received genetic input from crossings with Dutch pigs and perhaps pigs originating from Africa during the slave trade (Vianna, 1985). Brazilian native breeds are used to provide not only meat but also fat to local communities, and are reared on small rural properties and adapt well to precarious management conditions, and due to their hardiness they require little nutritional and sanitary care (França, 1991). However, in the last decade the tendency has been towards other imported commercial pig breeds and relatively few native Brazilian pigs stocks remain because their primary phenotypic trait, fat production, is no longer of interest to the consumer and has become a limiting fact in the marketing of native breeds (Lopes et al., 2002).

Native breeds possess a great but unexplored potential for the formation of reference populations and for the study of linkage maps and of the effects of quantitative trait loci and candidate genes. In addition to their extreme phenotype in terms of fat and meat deposition compared to that of commercial breeds, native breeds can be characterized by their extreme resistance to precarious management conditions and diseases (Guimarães and Lopes, 2001). Irgang (1986) stated that the preservation of the genetic potential of these breeds might be useful for eventual crossings aimed at increasing the hardiness of animals derived exclusively from imported breeds.

Pooling amplified DNA from parental sows has been reported to be an useful technique for sample sequencing (Rothschild and Soller 1999) and in our study pooling 6 animals per pool allowed us to optimize our experiments but did not impair the AgPAGE identification of polymorphisms even before samples sequencing. Despite our satisfactory results, it should be kept in mind that PCR is a competitive method, and fragments of various origins containing nucleotide variations at the primers annealing sites or even higher or lower degrees of purity differ in amplification efficiency. In these cases, important nucleotide variation might remain undetected.

Because $F_{1}$ animals were randomly selected it was not possible to have more $\mathrm{F}_{2}$ animals carrying the I and, especially, D allelic variants, further work being needed to genotype another population to find these variants and then proceed with selective matings to produce a larger number of pigs with mutant MYF5 alleles.

The primers used in our study were designed based on the Y17154 GenBank sequence according to which exon 1 is located between nucleotides 836 and 1501, exon 2 between nucleotides 2308 and 2383, and exon 3 between nucleotides 2802 and 3593 . This suggests that the nucleotide changes described by us are situated within exon 3. However, according to the sequence described by te Pas et al. (1999) exon 1 is located between nucleotides 1001 and 1501, exon 2 between nucleotides 2307 and 2387, and exon 3 between nucleotides 2801 and 2990 and, therefore, the 
Table 2 - Performance, carcass and meat quality traits for $\mathrm{F}_{2}$ generation normal/normal (NN) and normal/insertion (NI) genotypes in.

\begin{tabular}{|c|c|c|c|c|c|c|}
\hline \multirow[t]{3}{*}{ Trait } & \multicolumn{6}{|c|}{ Genotypes } \\
\hline & \multicolumn{3}{|c|}{ Normal/normal } & \multicolumn{3}{|c|}{ Normal/insertion } \\
\hline & $\mathrm{n}$ & Mean & sd & $\mathrm{n}$ & Mean & sd \\
\hline \multicolumn{7}{|l|}{ Performance traits* } \\
\hline Birth weight (BW) & 250 & 1.20 & 0.27 & 84 & 1.17 & 0.26 \\
\hline Weight at 21 days $\left(\mathrm{W}_{21}\right)$ & 186 & 4.93 & 1.05 & 72 & 4.92 & 0.99 \\
\hline Weight 77 days $\left(\mathrm{W}_{77}\right)$ & 197 & 21.43 & 3.99 & 79 & 20.30 & 4.20 \\
\hline Weight at 105 days $\left(\mathrm{W}_{105}\right)$ & 193 & 35.95 & 6.06 & 78 & 34.95 & 5.98 \\
\hline weight at slaughter (WS) & 220 & 65.10 & 5.53 & 71 & 65.98 & 4.97 \\
\hline Feed intake (FI) & 240 & 40.07 & 7.93 & 83 & 39.10 & 8.25 \\
\hline Average daily weight gain (ADG) & 236 & 0.52 & 0.14 & 81 & 0.54 & 0.11 \\
\hline Feed-gain ratio from 77 to $105(\mathrm{FG})$ & 236 & 2.91 & 0.76 & 81 & 2.70 & 0.58 \\
\hline Age at slaughter (AS) & 229 & 148.91 & 10.00 & 72 & 150.24 & 10.23 \\
\hline \multicolumn{7}{|l|}{ Carcass traits } \\
\hline Mean carcass length (MLC, cm) & 216 & 71.79 & 3.29 & 68 & 71.68 & 3.05 \\
\hline Backfat thickness at last 2nd-3rd thoracic vertebrae (SH, mm) & 216 & 41.32 & 5.83 & 70 & 40.91 & 5.44 \\
\hline Backfat thickness after last rib at $6.5 \mathrm{~cm}$ from the midline $(\mathrm{P} 2, \mathrm{~mm})$ & 217 & 16.98 & 3.64 & 70 & 17.70 & 3.95 \\
\hline Loin depth (LD, mm) & 194 & 43.30 & 4.33 & 63 & 44.08 & 4.41 \\
\hline Loin eye area (LEA, $\left.\mathrm{cm}^{3}\right)$ & 201 & 26.52 & 3.70 & 66 & 26.00 & 3.56 \\
\hline Total ham weight (THW, kg) & 230 & 7.29 & 0.86 & 73 & 7.31 & 0.83 \\
\hline Skinless and fatless ham weight (HW) (kg) & 228 & 5.03 & 0.61 & 72 & 5.03 & 0.60 \\
\hline Total (bone in) loin weight (TLW, kg) & 227 & 3.52 & 0.47 & 73 & 3.50 & 0.50 \\
\hline Loin weight $(\mathrm{LW}, \mathrm{kg})$ & 228 & 1.05 & 0.18 & 72 & 1.05 & 0.18 \\
\hline Carcass yield (CY, \%) & 213 & 82.03 & 2.28 & 67 & 82.04 & 2.08 \\
\hline \multicolumn{7}{|l|}{ Meat quality traits } \\
\hline $\mathrm{pH}$ of the meat 45 min after slaughter $\left(\mathrm{pH}_{45}\right)$ & 212 & 6.52 & 0.26 & 69 & 6.50 & 0.28 \\
\hline $\mathrm{pH} 24$ hours after slaughter $\left(\mathrm{pH}_{24}\right)$ & 214 & 5.72 & 0.17 & 69 & 5.74 & 0.16 \\
\hline Lightness (L) & 197 & 44.98 & 1.78 & 60 & 45.41 & 2.18 \\
\hline Redness (A) & 195 & 0.69 & 0.57 & 59 & 0.71 & 0.67 \\
\hline Yellowness (B) & 197 & 6.61 & 0.58 & 60 & 6.59 & 0.55 \\
\hline Intramuscular fat (IMF, \%) & 201 & 1.55 & 0.53 & 61 & 1.64 & 0.69 \\
\hline Drip loss (DL, \%) & 216 & $3.14^{\mathrm{a}}$ & 1.56 & 69 & $3.69^{\mathrm{b}}$ & 2.08 \\
\hline Cooking loss (CL, \%) & 217 & $32.26^{\mathrm{a}}$ & 2.41 & 69 & $33.21^{\mathrm{b}}$ & 2.31 \\
\hline Total loss (TL, \%) & 192 & $34.16^{\mathrm{a}}$ & 2.63 & 56 & $34.97^{\mathrm{b}}$ & 2.78 \\
\hline Objective tenderness $(\mathrm{OT}, \mathrm{g} / 1.2 \mathrm{~cm})$ & 187 & 5551.4 & 823.67 & 56 & 5759.1 & 916.65 \\
\hline Hue angle (h) & 189 & 83.71 & 5.19 & 54 & 83.63 & 6.31 \\
\hline Chroma (c) & 192 & 6.68 & 0.55 & 56 & 6.67 & 0.48 \\
\hline
\end{tabular}

*All in $\mathrm{kg}$, except for FG which is in $\mathrm{kg} / \mathrm{kg}$. $\mathrm{n}=$ number of observations; $\mathrm{sd}=$ standard deviation of the mean.

Means in the same row followed by different letters were significantly different by the $\mathrm{F}$ test at $\mathrm{p}<0.05$.

changes seen by us would be located in the untranslated 3' region of the gene. Since no protein sequence derived from the translation of the pig MYF5 gene has been reported in the literature so far, comparison of the gene sequence with the translated amino acid sequence is not possible and, therefore, the protein alterations generated by the allelic variants cannot be verified. If the sequence described by te
Pas et al. (1999) is correct, the changes observed would be markers without any expected phenotypic effect and, due to their proximity to exonic regions, would be in linkage disequilibrium with the translated region of the gene.

However, the chromosome region $5 \mathrm{q} 25$, in which the MYF5 gene locus is situated contains another gene, insulin-like growth factor I (IGFI), which might exert a similar 
function. In addition, myogenic factor 6 has recently been located on chromosome 5 of pigs (Vykoukalova et al., 2003) and also in humans and mice (Patapoutian etal, 1993; Floss et al., 1996) on the same chromosome as MYF5. It should also be remembered that our study used a $F_{2}$ pig population which may have had a high degree of linkage disequilibrium not only for the MYF6 or IGFI genes but also for as yet undiscovered genes.

Our study shows that in the $\mathrm{F}_{2}$ population studied the Insertion (I) variation in the MYF5 gene is associated with effects on meat quality traits, with pigs carrying the MYF5 Insertion variant having meat with a lower water-holding capacity. The Insertion allele came not only from a native Piau boar but also from 2 parental sows that carried Pietrain breed genes so it needs to be verified whether or not this polymorphism is unique to the Piau breed. This could be achieved by analyzing commercial herds, especially those containing Pietrain pigs for the MYF5 Insertion variant and studying its association with meat quality traits. This analysis could provide information about a putative Quantitative Trait Loci (QTL) for meat quality traits in Sus scrofa Chromosome 5 (SSC5).

The difference in meat yield between carcasses is related to variation in the number of muscle fibers determined during the embryonic period (hyperplastic phase). As mentioned earlier, muscle fiber formation in mammals is an embryonic process mediated by the MyoD gene family. After slaughter, muscle becomes the major part of the meat produced and it may be assumed that the different genes that control the muscular hyperplastic process regulate variation in growth rate, carcass traits and meat quality of the animals. Consequently, if the number of muscle fibers is determined during embryonic life and regulated, in part, by the four genes of the MyoD family, polymorphisms in these genes can have an effect on traits related to pork production and quality.

Te Pas et al. (2000) found an increase in mRNA expression for myogenin, MYF5 and MYODI in the muscle tissue of pigs selected for rapid growth compared to those selected for lean growth. In another study, te Pas et al. (1999b), analyzed a polymorphism in the myogenin gene using Polymerase Chain Reaction - Restriction Fragment Length Polymorphism (PCR-RFLP) using the Msp I enzyme and identified two alleles (A and $\mathrm{B}$ ) and observed that the BB genotype was associated with increased birth weight, growth rate and lean meat content without affecting subcutaneous fat thickness. However, te Pas et al. (1999a) found no significant associations between the allelic forms of the MYF5 gene and meat production traits.

In our study, statistically significant differences ( $p<0.05)$ were observed for drip loss, cooking loss and total loss between the NN and NI genotypes, with the NI genotype showing the highest values (i.e. undesirable traits). These traits might be related to the quantity or quality of muscle protein after slaughter. The Insertion variant was re- sponsible for only a small proportion of the phenotypic variance in drip loss $(2.2 \%)$, cooking loss $(2.9 \%)$ and total loss $(3.2 \%)$.

Since higher drip loss, cooking loss and total loss mean values were obtained for animals carrying the Insertion variant, this allele might be related to poor muscle protein quality or a reduction in the quantity of muscle protein in animals with this variant, this is supported by the fact that the normal allele was associated with a higher water-holding capacity. Meat with a lower $\mathrm{pH}$ shows, a priori, greater protein denaturation and since proteins are responsible for water retention in meat, more preserved proteins would reduce drip loss, cooking loss and total loss. In physical terms, a cut of meat with more preserved protein molecules would retain more water, while a smaller amount of intact protein leads to a lower water-holding capacity with greater losses during the handling processes (cutting, storage, cooking, etc.). Since no significant difference $(p=0.42$ for $\mathrm{pH}_{45}$ and $\mathrm{p}=0.57$ for $\mathrm{pH}_{24}$ ) in meat $\mathrm{pH}$ (Table 2) was observed between the genotypes, other factors such as the amount of muscle protein may have been responsible for the observed results.

Among the traits used to assess meat yield in pigs, the loin eye area (LEA) shows the best correlation with water-holding capacity. When analyzing the meat quality of the $\mathrm{F}_{2}$ animals genotyped in our study, Benevenuto Júnior (2001) found a significant correlation $(p<0.01)$ between LEA and drip $(r=0.22)$ and cooking loss $(r=0.15)$. Since LEA is a predictor of meat yield, the lack of a significant difference $(p=0.300)$ for this trait between the NN and NI MYF5 genotypes investigated in our study suggests that the $\mathrm{NN}$ and NI genotypes do not influence protein deposition in muscle and, consequently, meat yield. We also found no statistical differences between the NN and NI genotypes (Table 2) in respect to carcass traits, so these genotypes may act through variation in the quality of muscle protein, which may show greater denaturation followed by a lower water-holding capacity even under similar $\mathrm{pH}$ conditions, as was the case of our study. The lower water-holding capacity of the NI genotype seems to be due to some kind of mechanism associated or linked with the allelic Insertion variant, although because we did not determine sarcomere length or other similar measurements more work is needed to confirm this hypothesis.

The literature shows that the MYF5 gene is overridden by other genes such as the MYOD I gene, which results in the reduction of deleterious effects due to mutations in any of these genes. Therefore, in order to assess the real dimension of the effects of MYF5 and MYOD I on muscle development, the other genes of the MyoD family responsible for hyperplastic muscle development are currently being studied. The identification of allelic variants in the genes of the MyoD family will help in the analysis of the interactions between different genes, especially those ones of this family, acting on muscle development. 


\section{Acknowledgements}

The authors are grateful to Dr. Max F. Rothschild for his critical review of the manuscript and to the Brazilian agencies CNPq, CAPES and FAPEMIG for financial support.

\section{References}

Benevenuto Júnior AA (2001) Avaliação de rendimento de carcaça e de qualidade da carne de suínos comerciais, de raça nativa e cruzados. Dissertação de Mestrado, Universidade Federal de Viçosa, Viçosa, 93 pp.

Bergstrom DA and Tapscott SJ (2001) Molecular distinction between specification and differentiation in the myogenic basic helix-loop-helix transcription factor family. Molecular Cell Biology 21:2404-2412.

França LR (1991) Análise morfofuncional da espermatogênese de suínos adultos da Raça Piau. Dissertação de Mestrado, Universidade Federal de Minas Gerais, Belo Horizonte, 185 pp.

Floss T, Arnold HH and Braun T (1996) MYF5(m1)/Myf-6(m1) compound heterozygous mouse mutants down-regulate MYF5 expression and exert rib defects: Evidence for longrange cis effects on MYF5 transcription. Developmental Biology 25:140-147.

Guimarães SEF and Lopes PS (2000) Use of native genetic resources as a tool for the genomic mapping in swine In Proceedings Rare Breeds International Simposium (Digital publishing), 20-24 November 2000, Brasília, Brasil.

Irgang R (1996) Suínos de raças nativas: O interesse da pesquisa. Suinocultura Industrial 87:13-20.

Lopes PS, Guimarães SEF, Pires AV, Soares MAM, Carmo FMS, Martins MF, Benevenuto Júnior AA and Gomide LAM (2002) Results of performance, carcass yield and meat quality traits of $f 2$ crosses between brazilian native and commercial pigs for QTL mapping. In: Proceedings Word Congress in Genetics and Animal Livestock Production, v. 32:37-40, 17-23 August 2002, Montpellier, France.

Patapoutian A, Miner JH, Lyons GE and Wold B (1993) Isolated sequences from the linked MYF5 and MRF4 genes drive distinct patterns of muscle-specific expression in transgenic mice. Development 118:61-69.

Rothschild MF and Soller M (1999) Candidate gene analysis to detect traits controlling traits economic importance in domestic livestock. In: Proceedings Simposio Internacional de Genética e Melhoramento Animal, pp 219-242, 21-24 September 1999, Animal Science Department, UFV, Viçosa, MG.

Rychlik W (1993) Selection of primers for polymerase chain reaction. In: White BA (ed) Methods in Molecular Biology. Human Press, Totowa, pp 31-40.

te Pas MF, Verburg FJ, Gerritsen CL and de Greef KH (2000) Messenger ribonucleic acid expression of the MyoD gene family in muscle tissue at slaughter in relation to selection for porcine growth rate. Journal of Animal Science 78:6977.

te Pas MF, Somillion A, Hardes FL, Verburg FJ, van der Bosch TJ, Galesloot P and Meuwissen TH (1999a) Genetic variation at the porcine MYF5 gene locus. Lack of association with meat production traits. Mammalian Genome 10:123127.

te Pas MF, Somillion A, Hardes FL, Verburg FJ, van der Bosch TJ, Galesloot P and Meuwissen TH (1999b) Influences of myogenin genotypes on birth weight, growth rate, carcass weight, backfat thickness, and lean weight of pigs. Journal of Animal Science 77:2352-2356.

Vianna AT (1985) Os Suínos. 14a edição. Editora Nobel, São Paulo, 384 pp.

Vykoukalova Z, Knoll A, Dvorak J, Rohrer GA and Cepica S (2003) Linkage and radiation hybrid mapping of the porcine Myf 6 gene to chromosome 5. Animal Genetics 34:238.

Associate Editor: Pedro Franklin Barbosa 